\title{
Analysis of Real-Life Working Processes, Competencies and Operational Fields for the Usage in Vocational IT Education - Results of an Empirical Study Based on Job Offers
}

\author{
Simone Opel and Axel Wellesen \\ University of Duisburg-Essen, Essen, Germany \\ simone.opel@uni-due.de, axel.wellesen@gmx.de
}

\begin{abstract}
One part of professional IT (information and communication technologies) and CS (computer science) education in Germany takes place in vocational schools. For deeper interlocking of theory and practice, the curriculum is oriented towards the concept of learning fields ("Lernfelder") which are based on real-life working processes. As this concept differs from traditional curricular concepts, teachers only seldom put this concept into practice due to a lack of appropriate teaching material and deeper and valid knowledge on possible underlying working processes. For this reason, the following question arose: What are these working processes? To answer this question, we conducted an empirical study and analysed 100 job offers for computer specialists from online job agencies to explore their task descriptions and the demanded requirements. These descriptions have been assigned to a specially developed categorisation system which made it possible to reference these real-life operational fields and demanded competencies to the curriculum and its learning fields. As a result it appears that most of the described tasks are directly related to the technical aspects of IT Systems. The most demanded requirements have been social skills and good skills in English language. On this basis, a next step in this project will be the development of a general description of all competencies to be gained for the profession of computer specialist during vocational training.
\end{abstract}

Keywords: Vocational IT Education, Vocational CS Education, Empirical Study, Learning Fields, Operational Fields, CS Working Areas, Working Skills, Working Processes.

\section{$1 \quad$ Introduction}

Dual vocational education is a core element of the German educational system (2012: 551.272 new beginners in vocational education ([1], p. 7) vs. 495.088 first-yearstudents [3]). Dual vocational education consists of practical training at a company and theoretical education at school. In contrast to general secondary schools, the main intention of vocational schools is to teach relevant topics for the students' professional life to support development of working skills and professional action 
competency ([2], p. 14). Therefore, the curriculum also for the profession as computer specialist ("Fachinformatiker") is oriented towards the concept of learning fields. Learning fields describe the competencies that students should achieve and specific content the students should know ([2], p. 10). For a better integration of theory and practice, each learning field has been based on characteristic real-life working processes. They are supposed to be put into practice by implementing "learning situations". Although this concept leaves room for creative implementation and therefore contains high potential for the development of varied activity-oriented learning situations, the concept is rarely put into practice.

To explore these reasons, Opel and Brinda [5] [7] conducted an study with vocational school teachers. They could show that teachers in general are not familiar with the concept, but open-minded and motivated to implement it. However, they also revealed that "a significant part of the participants in the survey does not really know what it means to implement learning fields into learning situations. "([7], p. 156). The study also revealed that there are publications about the basics of the concept, but only very few about teaching with learning fields. In another interview study among IT and CS Training companies, Opel and Brinda [6] asked for typical working processes in the field of IT and CS. They came to the conclusion that most working processes cover main aspects of different learning fields, which corresponds to the results of the present work. However, the interviewed trainers mentioned that they would like to see more interdisciplinary projects, as well as activity-oriented and self-organised learning methods being put into practice at vocational schools. This could be achieved by consequently implementing the concept of learning fields.

To solve this problem, there is a larger project aiming at the development of a normative competence structure model, exemplary teaching material, tools and guidelines for creating learning situations using the learning field concept as well as a description of competencies the students should gain. Since learning fields are based on real-life working processes, this work contributes to these intentions by acquiring and analysing real-life operational fields, working processes and demanded competencies and how they are weighted in vocational reality.

\section{Related Work}

To enhance the acceptance of the curricular concept of learning fields, extended cooperation between companies and vocational schools could be useful. Repp et al. [11] discussed a project where apprentices as computer specialists for application development work on real projects from a nearby software company. After designing, realising and testing, the students present the project at the company and hand over the developed software. This way, a close connection with the vocational world can be achieved, which increases the motivation of the students. Furthermore, it offers the opportunity to integrate current technological and organisational developments from companies in vocational schools. Especially in the field of software development, there are chances for activity-oriented implementations of the according learning field by following professional software development process definition and thus represent real-life working processes. In contrast, there are no such implementations of learning fields concerning the field of IT Systems and networks. Instead, topics are treated in 
separate lessons and not in a wider context. This can cause problems when it comes to transfer the skills to vocational praxis [4].

Another study among over 600 companies and over 1000 apprentices [9] [10] explored IT working processes and education in business practice. The study revealed that lessons in vocational schools need to be improved because apprentices considered the demanded level to be too low. Furthermore, the apprentices criticised the lack of real-life relevance of the curriculum which could lead to a negative image of vocational schools. To improve this situation, the "SEDIKO" project aimed at designing learning fields as well as learning rooms [8]. After analysing and implementing the eleven learning fields, the conclusion was that these learning fields would only partially represent real-life working processes, since each single learning field only represents a part of a working process. The whole process can only be covered by their sum. This leads to the question whether there are learning fields that cover more of the demanded skills and competencies than others - and whether they should therefore be put into focus by vocational teachers.

All these studies confirm that the concept of learning fields seems to have a high potential which is not used consistently. A solution to this problem could be - besides a comprehensive description of competencies needed for the profession of computer specialist - the support of teachers by providing them exemplary material as well as guidelines for designing lessons based on the most demanded real-life working processes and skills.

\section{$3 \quad$ Methodology}

For a nationwide overview, we retrieved empirical data from 100 job offers listed in four of the biggest online job agencies: stepstone, monster, jobscout 24 and the job market of the Federal Employment Agency ("Jobbörse der Bundesagentur für Arbeit"). Each job offer was analysed according to the demanded requirements and the described tasks. Both aspects were collected in two separate profiles. Requirements represent the competencies directly demanded by the companies. These include personal, operational and professional competencies as well as formal requirements and experience. Tasks represent the vocational operational fields and describe the tasks themselves as well as the area in which they take place (see fig. 1). Based on this data, a categorisation was developed by using an inductive approach. We defined a multi-level category system for requirements and tasks each. The resulting categories have been directly derived from job descriptions by using methods of content analysis and will be described in detail in the next section.

\section{$4 \quad$ Results}

To structure the data, we defined three generic terms in the task profile (Systems Administration, Software Engineering, Other) and five in the requirements profile (IT-technical area, Support and Documentation, Soft Skills and Other, Operational Processes and Structures, Formal Requirements). Each of them was further divided into several subcategories (see fig. 1). 


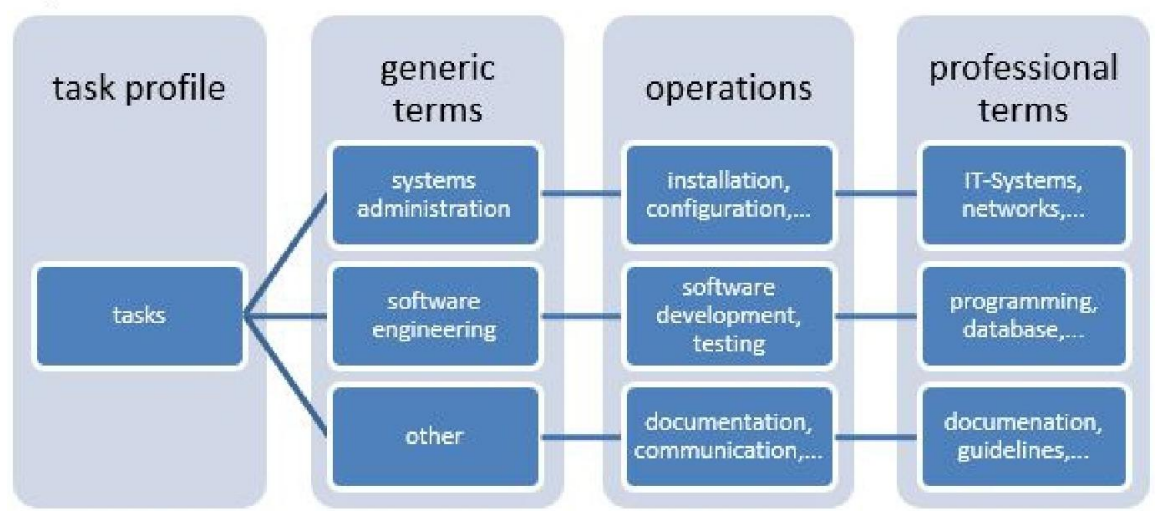

Fig. 1. Example from the task profile

The core elements which structure the generic terms, are operations (e.g. installation, support) or competencies (e.g. the ability to communicate) and professional terms that give a more detailed description of the area in which the operations take place (e.g. installation of software/hardware).

The core elements which structure the generic terms, are operations (e.g. installation, support) or competencies (e.g. the ability to communicate) and professional terms that give a more detailed description of the area in which the operations take place (e.g. installation of software/hardware).

Thus, it is possible to reference the retrieved data with the curriculum and the goals and contents of the learning fields. Each task and each requirement was put into one of the categories by using keywords from their description. Categories that described similar things or could not clearly be divided have been summarised afterwards. At last, the resulting categories were assigned to the eleven learning fields in two steps. The first assignment was based on direct references, which means that the tasks and requirements described in the category had to be directly mentioned in the definition of the learning field. The second assignment was based on indirect references. These represent the previous knowledge that is additionally needed to successfully accomplish the required tasks. Figure 2 shows an excerpt of a matrix which contains the correlation between the three most demanded skills / working processes and the respective learning fields.

The largest number of mentioned tasks with a direct reference to the skills and contents were listed in the learning fields that cover IT Systems in general ("Maintenance of IT Systems", "Simple IT Systems" and "Networked IT Systems"). This emphasises the well-filled categories "user-support", "maintenance and updates", "fault analysis and correction" and "software configuration and administration".

The most frequently demanded previous knowledge in the task profile originated from the learning field "Sources of information and working methods". Further learning fields that provide important previous knowledge for a successful accomplishment of the demanded tasks were "Professional English for technical occupations" and "Business processes and operational organisation". 


\begin{tabular}{|c|c|c|c|c|c|c|c|c|c|}
\hline & Learning fields & 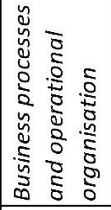 & 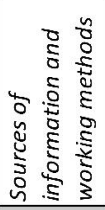 & 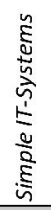 & 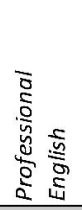 & 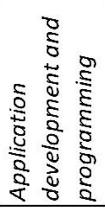 & 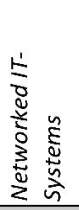 & 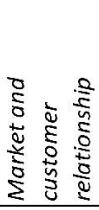 & 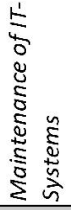 \\
\hline \multirow{3}{*}{ 产 } & $\begin{array}{l}\text { SW configuration } \\
\text { \& administration }\end{array}$ & b & b & a & b & & a & b & a \\
\hline & \begin{tabular}{|l|}
$\begin{array}{l}\text { Fault analysis \& } \\
\text { correction }\end{array}$ \\
\end{tabular} & & b & a & & & b & & a \\
\hline & User support & & b & b & b & & b & & a \\
\hline \multirow{3}{*}{ 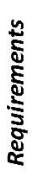 } & OS \& SW-Servers & & b & a & b & & a & b & a \\
\hline & General SW skills & & & a & b & & a & b & a \\
\hline & $\begin{array}{l}\text { SW development } \\
\text { \& testing }\end{array}$ & b & b & & b & a & b & & \\
\hline
\end{tabular}

a: Skill or working process references directly to the skills and contents of the learning field b: Skills and contents of the learning field are used as previous knowledge for a task or requirement Dark arev: most freauentlv mentioned - liaht arev: least freauentlv mentioned

Fig. 2. Learning fields and assigned tasks and requirements

According to the direct references to the skills and contents of the learning fields, the results for the requirements profile are similar. Differences appeared in terms of previous knowledge. Overall, most of the descriptions in the requirement profile were assigned to the learning field "Market and customer relationships", due to its relevance as previous knowledge. Furthermore, frequently demanded previous knowledge derived from the learning fields "Business processes and operational organisation", "Professional English for technical occupations" and "Sources of information and working methods".

The category "Soft skills and other" was evaluated separately, because its competencies are usually not domain-specific and thus cannot be assigned to a single learning field. The only exception is the subcategory "Knowledge of English", which can be clearly assigned to the learning field "Professional English for technical occupations". The largest number of mentions could be found in this category (demand in $56.0 \%$ of all job offers). Of similar importance are the demanded social skills "communication skills" (51.0\% of all job offers) and "Ability to work in teams" (44.0\% of all job offers).

Overall, the majority of working processes originate from the field of IT Systems in general, whereas the demanded previous knowledge occasionally varies, depending on the branch of business.

\section{Conclusion}

The question of this study was: What are the real-life working processes of computer specialists? The results show that the main topics all deal with IT systems in general. The most sought-after skills and competencies therefore derive from the learning fields "Networked IT Systems", "Simple IT systems" and "Maintenance of IT systems". The demanded tasks and skills involve installation, configuration, administration and support. The most sought-after previous knowledge can be 
assigned to the learning fields "Professional English for technical occupations", "Sources of information and working methods" and "Market and customer relationships". It could be valuable for vocational schools to focus on these learning fields in developing learning situations, since they represent the main aspects of the real-life working processes in the field of IT and CS. In addition, the development of social skills must be better taken into consideration across all learning fields.

The next steps will be to connect all data to a normative competence model for vocational computer science education as a general description of all competencies to be gained, furthermore the development of exemplary learning situations based on these results as well as suitable guidelines to support vocational teachers in developing their own lessons.

\section{References}

1. BMBF - Federal Ministry of Education and Research (Bundesministerium für Bildung und Forschung). Berufsbildungsbericht 2013 (German), Bonn, Berlin, Germany (2013)

2. CMECA - Standing Conference of Ministers of Education and Cultural Affairs (Sekretariat der ständigen Konferen der Kultusminster der Länder in der Bundesrepublik Deutschland. Rahmenlehrplan für den Ausbildungsberuf Fachinfor-matiker/Fachinformatikerin (German). beschluss der Kultusminsterkonferenz vom (April 25,1997)

3. Destatis - German Federal Statistical Office (Statistisches Bundesamt). Studien-anfänger/innen (2014)

4. Johlen, D.: Lernfeldübergreifender Zugang zu Betriebssysten und zur Netzwerktech-nik mit den Methoden der objektorientierten Programmirtechnik für die IT-Berufe (German). In: Hubwieser, P. (ed.) Informatische Fachkonzepte im Unterricht, IN-FOS 2003, Garching bei München, September 17-19, vol. P-23, p. 10. GI-Fachtagung Informatik und Schule (2003)

5. Opel, S., Brinda, T.: Learning Fields in Vocational IT Education - Why Teachers Refrain From Taking an Opportunity. In: Knobelsdorf, M., Romeike, R. (eds.) Proceedings of 7th Workshop in Primary and Secondary Computing Education (WiPSCE 2012). ACM, New York (2012)

6. Opel, S., Brinda, T.: Arguments for contextual teaching with learning fields in vocational it schools: Results of an interview study among it and cs training companies. In: Proceedings of the 8th Workshop in Primary and Secondary Computing Education, WiPSCE 2013, pp. 122-131. ACM, New York (2013)

7. Opel, S., Brinda, T.: Learning Fields in Vocational IT Education - How Teachers Interpret the Concept. In: Diethelm, I., Mittermeir, R.T. (eds.) ISSEP 2013. LNCS, vol. 7780, pp. 147-158. Springer, Heidelberg (2013)

8. Petersen, A.: Neue Lernfeld- und Unterrichtsgestaltung in den IT-Berufen. Ergeb-nisse und Erkenntnisse aus dem Meodellversuche und Verbundprojekt SEDIKO (German). Lernen und Lehren (68), 161-167 (2002)

9. Petersen, A., Wehmeyer, C.: Die neuen IT-Berufe auf dem Prüfstand. Erste Ergebnisse der bundesweiten IT-Studie (German). Berufsbildung in Wissenschaft und Praxis (bwp), (6) (2000)

10. Petersen, A., Wehmeyer, C.: Aufgedeckt: IT-Arbeitsprozesse und Ausbildung in der Betriebspraxis (German) (2003)

11. Repp, S., Ziegler, R., Meinel, C.: Lernortkooperation in der IT-Ausbildung Kompetenzentwicklung in Projekten (German). In: Schubert, S. (ed.) Proceedings of the 2007 German conference on Informatics and Schools (INFOS 2007), pp. 135-146. Köllen, Bonn (2007) 